
Informations

une revue Gallia

Lorraine | 2001

\title{
Ennery
}

Pôle industriel Garolor, sites 1 et 17

\section{Franck Thiériot}

\section{(2) OpenEdition \\ 1 Journals}

Édition électronique

URL : http://journals.openedition.org/adlfi/8878

ISSN : 2114-0502

Éditeur

Ministère de la culture

Référence électronique

Franck Thiériot, « Ennery », ADLFI. Archéologie de la France - Informations [En ligne], Lorraine, mis en ligne le 01 mars 2001, consulté le 27 avril 2019. URL : http://journals.openedition.org/adlfi/8878

Ce document a été généré automatiquement le 27 avril 2019

(c) Ministère de la Culture et de la Communication, CNRS 


\section{Ennery}

Pôle industriel Garolor, sites 1 et 17

\section{Franck Thiériot}

\section{Identifiant de l'opération archéologique : F1357200100031}

Date de l'opération : 2001 (SU)

1 La fouille conduite durant le printemps 2001 sur les sites 1 et 17 du pôle industriel «Garolor » à Ennery a porté sur une surface légèrement supérieure à $3000 \mathrm{~m}^{2}$. Cette intervention est limitrophe et constitue l'extension des recherches déjà réalisées sur le secteur « Servitherm » en 1992 (voir Bilan scientifique régional, 1992, p. 52-53). L'étude des matériaux issus de cette opération n'étant pas commencée, les données présentées ici ne seront que succinctes et indicatives.

La topographie de l'emprise est caractérisée par la présence d'un paléorelief correspondant au début d'un vallon ancien orienté nord-est - sud-ouest, déjà observé lors des interventions précédentes. Bien que peu marquée, cette anomalie a permis de préserver des sédiments anciens de l'érosion. Un décapage manuel a révélé la présence d'artefacts archéologiques sur une partie de cet horizon (céramique, faune, instruments de mouture, etc.). Bien que la surface observée soit modeste, l'hypothèse de la fossilisation d'un niveau d'occupation semble pouvoir être avancée. Le mobilier recueilli permet d'envisager une datation dans la seconde partie de l'âge du Bronze final. Plusieurs structures en creux sont associées à cette phase de l'occupation du site. Leur organisation ne permet pas de restituer de plan de bâtiments.

3 Les âges du Fer sont représentés par plusieurs fossés que l'on doit mettre en relation avec les vestiges de l'établissement indigène fouillés précédemment. 
INDEX

operation Sauvetage urgent (SU)

Index chronologique : âge du Bronze, âge du Fer

Thèmes : céramique du bronze, édifice, faune, fossé, mouture, occupation du sol

Index géographique : Lorraine, Moselle (57), Ennery

\section{AUTEURS}

\section{FRANCK THIÉRIOT}

AFAN 